contributed to advances in the design of compressors and of vessels to withstand high pressures. During the War, Prof. Newitt was in charge of the research work of the Inter-Services Research Bureau and was responsible for many important developments. $\mathrm{He}_{\mathrm{e}}$ is a member of the Heyworth Committee on the gas industry which has recently reported. He has also recently had the opportunity of visiting schools of chemical engineering in the United States of America. Prof. Newitt combines experience of research work in a wide field of engineering and physical chemistry with teaching experience which augurs well for the School of Chemical Engineering at the Imperial College.

\section{Card File of Physical Constants of Substances}

THe general plan of the American "Annual Tables of Physical Constants", started in 1941 under the Na. tional Research Council, called for publication of tables on loose sheets, by sections according to properties, and also of a card file of numerical data of physical magnitudes, by substances. The card file represents a departure from the customary method of recording and filing data dispersed in the literature. They are to be assembled in the card file for each substance in a permanent predetermined order of physical properties, instead of being tabulated for each property, for a list of substances. Thus all physical properties for a given substance are brought together, adding up to a complete numerical description of the substance; and the non-availability of certain data for the given substance becomes immediately noticeable by the absence of the section number of the corresponding property on the substance chart. The actual numerical values are inserted whenever they are expressible by a figure or a few figures ; extensive tables of data are not as a rule reproduced. It is expected that microfilm distribution facilities and reading devices will be available in the near future, so that one may obtain microfilm copies of any scientific publication desired. This will render extensive reproduction of voluminous tables superfluous and further justify the present scheme.

The cards are being planned as follows : Elements in the alphabetical order of their symbols, inorganic compounds in the alphabetical order of their formulæ, organic compounds also in the usual order of their overall formulæ by increasing numbers of the carbon and hydrogen atoms. However, as the data are on loose cards, users, if they choose, can re-order their card files by any other principle which they may prefer. As new numerical material is pub. lished, additional cards will be issued for substances already covered. Likewise revised cards will be supplied whenever necessary to replace old cards which may become obsolete. It is planned to issue about two thousand substance cards a year in instalments of a hundred cards. One drawback of the use of the small-sized card, 5 in. $\times 3$ in., is that it may involve a large number of cards per substance; for example, bromine requires eighteen cards. The subscription price is based on the rate of 5 cents a card, that is, 100 dollars a year for a set of 2,000 cards. Auxiliary cards will be supplied at 1.5 cents a card or 5 dollars for the set, whichever is the less. Publication at practically nominal prices has been made possible by grants and subsidies provided mainly by industrial corporations and a generous donation from the Carnegie Institution. Correspondence should be addressed to "Annual Tables of Physical Constants", Frick Chemical Laboratory, Princeton, New Jersey.

\section{The Association for Planning and Regional Recon-} struction

IN response to many requests, the Association for Planning and Regional Reconstruction has decided to develop its Information Service, and subscribers are now to be offered, in addition to copies of all the Association's broadsheets and reports and the services of the library and the information bureau, a bimonthly bulletin containing a report of work being undertaken by the Association as well as a résumé of matters of interest in the planning world and prepublication news of books produced by the Association to ensure subscribers being able to obtain these when published. The first information bulletin, October-November 1945, continues as No. 160 the progress sheets issued since February 1941. The bulletin includes a selected list of recent acquisitions to the Association's library, and a revised edition of Broadsheet O, dated September 1945, giving general information about the Association and containing a complete list of broadsheets issued to date, has also been published. The Association, which aims at serving as a centre for research in the planning field and undertaking factual investigations, as well as acting in an advisory capacity and furthering the establishment of technical and other standards, and the development of new conceptions of planning, works closely with the School of Planning and Research for Regional Development, which is under a separate board of management. The School has enrolled more than a thousand correspondence students in the Armed Forces and among prisoners of war, and those who on demobilization reach a certain standard are eligible for a three months completion course, the successful students in which will be exempt from the final examination of the Town Planning Institute.

\section{Training of Engineers}

IN his presidential address before the Institution of Mechanical Engineers, delivered on October 19, Prof. Andrew Robertson emphasized that the training of engineers is concerned very much with "a knowledge of science and the technique which must go with it", to which must be added qualities of character. The needs of a healthily advancing industry show that mechanical engineering can usefully absorb a considerable increase (twice the pre-war number is suggested), in the output of universities and technical colleges, of young men trained to the standards of engineering degrees or of higher national certificates. "There is a definite field for the technical college distinct from that of the faculty of engineering," the range of activity of the former being from crafts at one end to higher national certificate and specialized technological work at the other. "The aim of a university department should be to produce potential leaders of the profession."

National certificate courses, successfully begun twenty-four years ago, should be further developed; part-time day release should be encouraged; opportunities for superior technical college students to attend full-time courses should be provided; the universities and industry should co-operate intimately in the production of scientifically trained men, not omitting college apprentices; engineering faculties should consider the advisability of instituting 'general honours' and 'special honours' degrees; the educational scheme of Britain should be so designed that at every stage promising students may be transferred to the course best suited to them; "there is 